\title{
Culture and Collaborative Technologies
}

\section{Susan R. Fussell}

Carnegie Mellon University

5000 Forbes Avenue

Pittsburgh, PA 15213 USA

sfussell@cmu.edu

\section{Qiping Zhang}

Long Island University

720 Northern Boulevard

Brookville, NY 11548

Qiping.zhang@liu.edu

\begin{abstract}
This workshop will explore interactions among culture, features of collaborative technologies, and group processes and outcomes. The workshop will address several key challenges to this area of research,

including identifying important dimensions of cultural variability, specifying how these dimensions interact with features of technology to impact group processes and outcomes, developing design specifications for multi-cultural and cross-cultural collaborative tools, and addressing methodological issues that arise in crosscultural research. Workshop goals include identifying key areas for future research, specifying initial design recommendations, fostering new collaborations among researchers interested in culture and computermediated collaboration, and, if there is sufficient interest among participants, creating an edited volume on this topic.
\end{abstract}

\section{Keywords}

Culture, cross-cultural interaction, computer-mediated communication, CMC, computer-supported collaborative work, CSCW

\section{ACM Classification Keywords}

H5.3. Information interfaces and presentation (e.g.

$\mathrm{HCI}$ ): Group and Organizational Interfaces - 
collaborative computing, computer-supported cooperative work.

K.4.3 [COMPUTERS AND SOCIETY]: Organizational Impacts: computer-supported cooperative work

\section{Introduction}

In their seminal paper on why distance matters, Olson and Olson ([5], p. 169) argued that, "possibly the single biggest factor that global teams need to address is culture differences." They go on to describe a number of important ways in which cultural differences in conventions, work processes, power relationships, conversational styles, and other areas can impact the success of a collaboration. Despite the clear and increasing importance of cultural variability, however, most behavioral research on computer-mediated collaboration and many of the technologies developed to support this collaboration have to date been rooted in Western cultures.

The aim of this workshop is to bring together researchers and developers with interests in the interaction between culture and the use of collaborative technologies. Through individual presentations and group discussion of central challenges, we aim to identify key areas for future research, specify initial design recommendations for tools for cross-cultural collaboration, foster new collaborations among researchers interested in culture and computermediated collaboration, and, if there is sufficient interest among participants, produce papers for an edited volume on this topic.

\section{Background}

Research from fields such as psychology, anthropology and sociology suggests that societies vary along a number of important dimensions that might be expected to influence how and why people use collaborative technologies and what features might be most desirable and/or useful for them. For example, several theorists have suggested that cultures differ along a dimension of individualism versus collectivism (e.g., [3][9]). Individualist, typically Western, societies emphasize individual initiative and prestige whereas collectivistic, typically Eastern, societies stress communal well-being and harmony.

Hall [2] proposed that cultures also differ in the extent to which contextual information is important for effective and satisfying communication. Low context, typically Western, cultures communicate primarily through verbal channels whereas high context, typically Eastern, cultures rely heavily on situational information (e.g., nonverbal behavior, interpersonal relationships).

Cultural dimensions such as individualism-collectivism and low vs. high context of communication may impact computer-mediated collaboration at many levels. They may determine what kinds of collaborations people choose to undertake and with what partners; they may impact process variables such as conversational grounding and trust development; and they may influence important outcomes including performance and group cohesion.

Several recent studies suggest that these dimensions of cultural variation interact with features of technology

(e.g., text vs. speech interfaces, audio vs. video conferencing) to impact group processes and outcomes. 
For example, Setlock et al. [7] found that Chinese-born participants conversed longer face-to-face than via instant messaging whereas American-born participants were equally terse in both media conditions. Zhang et al. [11] found that performance outcome was the same across pairs from different countries, but that trust in each other was lower for Chinese participants, overall, and lower still for Chinese communicating over audio only rather than audio plus video.

Despite these recent advances, however, we are far from having a detailed theoretical understanding of interactions among culture, technology and group processes and from having clear design recommendations for tools to support collaboration within multiple cultures and/or between cultures. This workshop attempts to address this situation by considering several major challenges, described in the next section.

\section{Workshop Structure}

The workshop is organized around three challenges facing cross-cultural research on collaborative technologies:

Challenge \#1: Developing a conceptual framework for the study of culture and collaborative technology. Research in the area of culture and collaborative technology has to date been scattered across multiple conferences and journals, including the $\mathrm{CHI}, \mathrm{CSCW}$, and GROUP conferences, the Hawaii International Conference on System Sciences (HICSS), and business and psychology journals. Studies vary widely in terms of how culture is defined, what technologies and cultures are studied, what methods are used, and how the data is analyzed. They also vary widely in terms of results: some find main effects of culture but no interactions with technology (e.g., [6]), some find interactions between culture and technology (e.g., [4][7]) and some demonstrate differences between homogeneous vs. heterogeneous groupings (e.g., $[1][8])$.

The first challenge of the workshop will be to bring some order to the diversity of existing studies by clarifying the similarities and differences among them, extracting elements that should be included in a broad framework for research on culture and collaborative technologies, and identifying critical research questions for future research.

Challenge \#2: Developing suitable methodologies for conducting research on culture and collaborative technologies.

Conducting research on collaborative work into a crosscultural setting invokes a host of methodological issues, including identifying potential collaborators in other countries, translating survey questions, experimental materials and/or interface elements, and recruiting participants. Investigators need to consider questions such as whether all participants should converse in the same language (e.g. English) or each should use their own native language (cf. [10]), and whether extra steps should be taken to ensure that participants from all cultures are in agreement on the goals and strategies involved in the collaboration, or whether these variations are instead a central aspect of culture that should not be factored out.

Participants will be asked to describe the methodological issues they have faced and, as a group, we will discuss strategies for resolving these issues. 
Our goal will be to identify some basic guidelines for conducting cross-cultural research on collaborative technologies.

Challenge \#3: Designing technologies to support multiple cultures and to facilitate cross-cultural interaction.

Finally, we will consider how our current knowledge of interactions between culture and collaborative technologies can be used to generate design recommendations. We will consider two interrelated issues: developing tools for use in same-culture groups in multiple different cultures and developing tools for cross-cultural interaction. Topics of discussion will include whether a given tool should include features that would make it valuable across multiple cultures or whether it might instead be preferable to design the best possible tool for each individual culture, ignoring the needs of other cultures in the process.

\section{Workshop Organization}

The two-day workshop will begin with a series of 20-30 minute presentations in which participants outline their culture-related research objectives, methodology and findings, methodological challenges they have faced and how these were resolved, and, where applicable, any specific tools they have designed for multi-cultural or cross-cultural use. From these presentations we will identify specific topics pertaining to each of the challenge areas outlined above that we will discuss as a group on the second day. By the end of the workshop, we aim to create a brief paper outlining our progress on each of the three challenge areas.

\section{References}

[1] Anderson, W. N. \& Hiltz, S. R. (2001). Culturally heterogeneous vs. culturally homogeneous groups in distributed group support systems: Effects on group process and consensus. Proceedings of HICSS 2001.

[2] Hall, E. (1976/1981). Beyond culture. NY: Doubleday.

[3] Hofstede, G. (2001). Culture's consequences': Comparing values, behaviors, institutions, and organizations across nations ( $2^{\text {nd }}$ ed.). Thousand Oaks, CA: Sage.

[4] Kayan, S., Fussell, S. R., \& Setlock, L. D. (in press). Cultural differences in the use of instant messaging in Asia and North America. Proc. CSCW 2006.

[5] Olson, G. M., \& Olson, J. S. (2000). Distance matters. Human-Computer Interaction, 15, 139-179.

[6] Reinig, B. A., \& Mejias, R. J. (2004). The effects of national culture and anonymity on flaming and criticalness in GSS-supported discussions. Small Group Research, 35, 698-723.

[7] Setlock, L. D., Fussell, S. R., \& Neuwirth, C. (2004). Taking it out of context: Collaborating within and across cultures in face-to-face settings and via instant messaging. Proc. CSCW 2004 (pp. 604-613).

[8] Setlock, L. D., Quinones, P. A., \& Fussell, S. R. (in press). Does culture interact with media richness? The effects of audio vs. video conferencing on Chinese and American dyads. Proceedings of HICSS 2007.

[9] Triandis, H. C. (1995). Individualism and collectivism. Boulder, CO: Westview Press.

[10] Yamashita, N. \& Ishida, T. (in press). Effects of machine translation on collaborative work. Proc. CSCW 2006.

[11] Zhang, Q.P., Olson, G.M. \& Olson, J.S. (2004) Does video matter more for long distance collaborators? Proceedings of XXVIII International Congress of Psychology. 